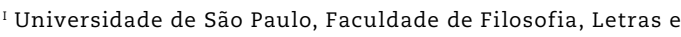

Ciências Humanas, Brasil

leninbicudo@gmail.com

Lenin Bicudo Bárbara'

\title{
A VIA ANALÓGICA NO PENSAMENTO DE GEORG SIMMEL'
}

\section{INTRODUÇÃO AO PROBLEMA}

Kracauer abre sua monografia sobre Simmel (ver Kracauer, 2004)² expondo a dificuldade peculiar imposta ao intérprete que pretenda rotular o campo das reflexões simmelianas. Como posteriormente outros intérpretes de Simmel enfatizariam, por trás dessa dificuldade está a plasticidade de seu estilo filosófico, que o dispunha a abordar temas os mais inusitados, explorar várias linhas de argumentação distintas e não raro contraditórias num mesmo ensaio, e transpor os limites costumeiros entre os vários domínios do conhecimento.

Se essa plasticidade deslumbrou vários ouvintes e leitores, incomodou profundamente outros, que viam nela incoerência e falta de rigor. Assim, entender melhor essa plasticidade tornou-se o grande desafio para seus intérpretes, que precisaram transcender tais impressões de leitura, localizando, na obra de Simmel, o núcleo problemático que alimenta impressões afinal tão diversas.

No presente artigo, esse problema mais geral será encarado de uma perspectiva bem específica. Proponho examinar uma das principais ferramentas de que Simmel se serviu para imprimir em sua obra a marca da plasticidade: a analogia. Para tal, traço um panorama geral dos vários usos e funções que o procedimento analógico assumiu no pensamento de Simmel, tal como este consolidou-se em seus livros de maior interesse sociológico: 
a Philosophie des Geldes (I900) e a Soziologie (I908) - buscando identificar como, e com que fins, Simmel valeu-se desse recurso para articular esses dois projetos intelectuais.

Os leitores de Simmel decerto terão na memória alguma de suas analogias, pois, só nas duas obras mencionadas, encontramos centenas delas. Dentre os que, além de leitores, também fizeram as vezes de comentadores de Simmel, não foram poucos os que se referiram à analogia como componente relevante de seu pensamento. Weber, Kracauer, Freyer, Tenbruck, Wolff, Levine, Frisby, Lichtblau, Vandenberghe, Dodd e Waizbort - todos ao menos tocaram no assunto, 4 e alguns chegaram a problematizá-lo, indicando o vínculo do recurso à analogia com aquela plasticidade que o próprio Simmel buscava. Voltaremos a alguns desses autores ao longo deste artigo.

Antes de tomar em mãos esse problema, gostaria que o examinássemos mais detidamente. Esse exame ocupará as duas primeiras seções do artigo. Na primeira, procuro expor o que eram as analogias para Simmel, reconstruindo os fragmentos da história do conceito mais pertinentes ao seu caso. Na segunda, trato das analogias tal como aparecem no texto simmeliano, mapeando suas ocorrências e funções básicas na Philosophie des Geldes e na Soziologie. Isso nos dará uma imagem mais precisa do problema, que nos permitirá confrontá-lo com maior propriedade. Reservo esse confronto à seção final do artigo, em que trato de vasculhar a relação do procedimento analógico com o tipo de pensamento a que Simmel adere.

\section{A ANALOGIA AOS OLHOS DE SIMMEL}

Em seu Sistema de Lógica, Stuart Mill afirmou não haver "palavra usada de forma mais vaga ou com tamanha variedade de sentidos do que 'analogia'" (Mill, I96I: 36I).5 Apesar do exagero, o termo possui mesmo um amplo espectro semântico, adquirindo sentidos marcadamente distintos nos vários contextos em que é utilizado. Por isto, o primeiro passo deste artigo consiste em selecionar o leque de sentidos mais pertinentes ao nosso caso. Para tal, em vez de propor uma definição fechada do conceito, reconstruirei o quadro de referências de que Simmel dispunha para formar sua própria ideia do que era uma analogia e de como usá-la adequadamente. Essa opção justifica-se pela circunstância de que o próprio Simmel não operava com um conceito perfeitamente fechado de analogia ${ }^{6}$ - embora possamos discernir dois pares de designações básicas do conceito que de certa forma orientaram os vários usos verificados na sua obra. Como, de resto, Simmel não inventa nenhuma dessas definições, mas apenas apropria-se delas, podemos, para chegar a tal reconstrução, consultar algumas das fontes que ele mesmo consultara - um esforço que, embora fragmentário, é crucial para evitarmos imputar ingenuamente a Simmel a nossa concepção de analogia. 
Encontramos na filosofia grega a primeira definição do conceito relevante para Simmel. Nesse contexto, a analogia aparece como um esquema cognitivo que se deixa expressar na seguinte fórmula: A está para B, assim como $C$ está para $D$. Encontramos instâncias desse esquema peculiar em textos tão antigos como os poemas de Safo (ver Snell, I992: 253), mas os primeiros registros de que se tem notícia do nome "analogia" ocorrem mais tarde, em particular em Architas de Tarento e Platão.7 Em Platão, que nos interessa por ser um autor com quem Simmel tinha certa familiaridade, encontramos inúmeros argumentos estruturados na forma de analogia; pensemos aqui na conhecida passagem da República em que Sócrates, visando demonstrar que a busca pela verdade depende da ideia do bem, argumenta que o Sol estaria para a visão (e seus objetos), assim como o bem para o intelecto (e seus objetos), concluindo que "aquilo que difunde a luz da verdade sobre os objetos do conhecimento e confere ao sujeito conhecedor o poder de conhecer é a ideia do bem" (Platão, 1965: 94). ${ }^{8}$

Embora tenha usado a palavra "analogia" e empregado inúmeras vezes a fórmula correspondente em seus diálogos - que Simmel, por apresentar-se como filósofo, não podia ignorar -, caberia não a Platão, mas a Aristóteles compor a primeira definição mais explícita do conceito. Aristóteles concebe a analogia como uma identidade de razões, em que a "razão" é concebida como uma relação entre dois termos. Tal modelo admite expressão aritmética e geométrica, trazendo consigo uma série de implicações: pois, se A está para B assim como C para D, então A está para C assim como B para D; e, se atribuirmos valores a três desses termos, podemos encontrar o quarto, contanto que a relação entre essas duas razões seja mesmo de identidade. ${ }^{9}$ Nesta chave matemática, analogia equivale a proporcionalidade..$^{\text {Io }}$

Aristóteles apresenta essa definição do conceito em sua Ética nicomaqueia, em que explicita sua origem matemática (ver Aristóteles, I984: 17851786). ${ }^{\text {II }}$ Apesar dessa origem, Aristóteles empregava analogias em vários contextos discursivos, como na Poética, em que fala da analogia como um dos princípios possíveis para a formação de metáforas. O exemplo clássico que fornece para isso - que reaparece na Retórica - é este: se o escudo está para Ares, assim como a taça para Dionísio, então o poeta pode dizer que "o escudo é a taça de Ares", ou então, mais elipticamente, que o "escudo é uma taça sem vinho" (Aristóteles, I984: 2332-2333). ${ }^{\text {I2 }}$ O que confere sentido a essas construções poéticas - o que nos faz lembrar do "escudo" mesmo quando o poeta, em vez de chamá-lo pelo nome próprio, menciona apenas a "taça de Ares" -, é a proporcionalidade acima mencionada, trivial no imaginário grego.

No texto de Simmel, podemos identificar inúmeras comparações que se encaixam perfeitamente nessa fórmula, que ele reconhecia como a fórmula da analogia. Assim, logo no primeiro capítulo da Soziologie, ele afirma que "a sociologia está para as demais ciências especializadas assim como a geo- 
metria para as ciências físico-químicas da matéria", e chama isso de analogia (Simmel, 1992: 25).

Mas nem todas suas analogias encaixam-se perfeitamente nessa fórmula, pois Simmel também chamava de "analogia" outro tipo de relação entre termos - que, embora derive da proporcionalidade, não se resume a ela. Para acessá-la, passaremos da filosofia grega à ciência moderna, e mais especificamente ao texto de Darwin, que teve um impacto importante na formação intelectual de Simmel.

Trata-se, aqui, do conceito de analogia como semelhança funcional. A certa altura d'A origem das espécies, Darwin distingue dois tipos de semelhança ou afinidade entre os traços dos animais (por exemplo: entre os braços dos seres humanos, as nadadeiras das baleias e as nadadeiras dos peixes). Darwin reserva o termo homologia às semelhanças estruturais hereditárias; neste sentido, os braços dos seres humanos são homólogos às nadadeiras das baleias. ${ }^{13}$ O conceito de analogia é definido por oposição ao de homologia: Darwin só considera dois traços análogos caso a semelhança aparente entre eles seja devida não à descendência comum, mas, sim, ao que hoje chamamos de adaptação convergente. Como exemplo, Darwin menciona a semelhança entre as nadadeiras dos cetáceos e a dos peixes, semelhança esta que nos induz a chamá-las pelo mesmo nome, e devida à circunstância de que, para sobreviver, tanto peixes como cetáceos acabaram desenvolvendo estruturas anatomicamente adequadas para a locomoção eficiente dentro d'água (ver Darwin, I964: 427-428).

O importante no contexto da recepção simmeliana das ideias de Darwin é que, enquanto o conceito de homologia prescinde da ideia de função (dois traços homólogos não precisam ter a mesma função), o de analogia ainda depende dela, ainda que num sentido específico. Pois parte da solução de Darwin para o problema da existência de membros similares, mas cuja semelhança não é herdada, consiste em referir tais estruturas a uma função comum, identificando "para que servem". Essa estratégia é ao menos tão velha quanto Aristóteles, mas Darwin vale-se dela num registro diferente do aristotélico. A diferença é que Darwin não se contenta em identificar a função comum que "explica" a semelhança de forma, mas avança com a explicação ao concebê-la como resposta adaptativa a certas pressões ecológicas - pressões essas de natureza sistêmica, ou melhor, oriundas de uma "teia de relações em que se unem plantas e animais distantes na escala da natureza" (Darwin, I964: 63). Em suma, o que afinal explica a semelhança formal e funcional que Darwin chama de analógica é sua remissão a certas condições de vida também semelhantes, a sua posição relativa na "cadeia da vida".

Simmel, como aliás outros sociólogos, lança mão de um modelo similar para relacionar formações sociais concretas. Assim, a certa altura de sua Soziologie, ele chama a atenção para a semelhança de função entre uma lei de 
Tebas, que fixaria o número de proprietários de terra, e uma lei de Corinto, que fixaria o número de famílias - indicando como nos dois casos o que estaria em jogo seria a "sobrevivência" das aristocracias locais (Simmel, I992: 67). ${ }^{\text {I4 }}$ Simmel se referia a esse tipo de convergência formal como analógica; e assim como, para Darwin, tal convergência não pressupunha nenhuma forma de transmissão hereditária, assim também, para Simmel, tal correlação entre formações sociais não pressuporia necessariamente mecanismos de transmissão histórica, de modo que tais formações poderiam desenvolver-se independentemente uma da outra.

Há várias diferenças importantes entre essas versões do conceito de analogia. Aqui destaco apenas duas delas. Noto, primeiramente, que a fórmula da analogia proporcional implica, no limite, uma identidade de razões, enquanto a segunda modalidade de analogia pressupõe apenas uma semelhança geral de forma e de função - sendo este, portanto, um conceito mais vago do que aquele. Em segundo lugar, enquanto a analogia na acepção matemática é uma equivalência puramente abstrata de relações (ou seja, uma relação de relações), a analogia na segunda acepção refere-se a entidades empíricas ou concretas (ou seja, é uma relação mais "aparente", uma relação entre coisas).

Isto basta para passar uma ideia básica do que era uma analogia aos olhos de Simmel. Porém, se tanto Aristóteles como Darwin estipularam certas normas para o uso adequado da analogia, tais normas pesavam, no contexto intelectual em que Simmel estava metido, muito menos do que aquelas prescritas por Kant e Goethe - a que devemos nos voltar para formar uma ideia mais precisa do leque de designações que o conceito de analogia adquire para Simmel.

Kant, que conhecia bem o conceito de analogia, uma vez chamou a atenção para que seu uso na filosofia era válido apenas como recurso heurístico ou regulador. Grosso modo, isto significa que uma analogia tem certo valor quando fornece parâmetros formais para a descoberta e conceituação de fenômenos novos, tornando conhecido algo até então desconhecido. Nas palavras de Heidegger, "com a analogia, obtemos apenas a indicação para uma relação de algo dado com algo não dado, ou seja, a indicação de como nós temos de procurar, a partir de algo dado, algo não dado, e de onde temos de achá-lo caso se apresente" (Heidegger, 1987: 177). ${ }^{\text {I5 }}$ Esta funcionalidade heurística ou reguladora pode ser pensada como uma qualidade cognitiva, como um recurso que, se adequadamente explorado, pode resultar em ganho cognitivo - e é esse ganho que Simmel teve em vista quando, por exemplo, sugeriu aplicar à sociologia "o princípio dos efeitos infinitamente múltiplos e infinitamente pequenos [...], que se mostrou eficaz nas ciências diacrônicas da geologia, da teoria biológica da evolução e da história" (Simmel, I992: 3334). A ideia, neste caso, é que a analogia com essas ciências orientaria o so- 
ciólogo a prestar atenção mesmo às formas mais sutis e voláteis de socialização ${ }^{16}$ (como a troca de cartas, a inveja, o segredo, a gratidão etc.), pois pode ser que elas desempenhem algum papel na manutenção da sociedade como um todo.

Goethe também fornece pelo menos duas prescrições que merecem destaque. Primeiro, sugere que a analogia deva ser usada com comedimento:

Tudo que existe é um analogon de todo o resto; daí que a existência apareça para nós sempre ao mesmo tempo ligada e separada. Se perseguirmos a analogia longe demais, tudo acaba por coincidir na identidade; se passarmos ao largo dela, tudo se dissipa na infinitude. Em ambos os casos, cessa a reflexão: num caso por viver em excesso, noutro caso, morta (Goethe apud Simmel, 2003: 95).

A leitura atenta dos textos de Simmel revela que ele também evitava "ir longe demais" com suas analogias - ora apontando os limites de determinada analogia, ora desmontando uma falsa analogia, ora enfatizando que certa particularidade não admite analogias.

Dodd recentemente chamou a atenção para um segundo aspecto da influência de Goethe sobre Simmel (e Benjamin) no tocante à analogia. Em seu artigo, ele compara as analogias que Goethe estabelece nos seus estudos de botânica àquelas empregadas por Simmel (Dodd, 2008). Isto indica que Goethe, cujas pesquisas nesta e em outras áreas eram marcadas por uma tentativa de fusão entre arte e ciência, pode ter sugerido a Simmel algo como um valor expressivo da analogia - ressaltando o imperativo de preservar uma qualidade estética da analogia mesmo ao empregá-la em contextos científicos. ${ }^{17}$

É possível reconstruir em maior detalhe esse quadro de referências, mas o que temos até aqui basta para os nossos fins. Nas seções seguintes, veremos como Simmel manejou esses vários fragmentos da história da analogia, examinando primeiro o que resultou desse manejo, para depois buscarmos pela lógica por trás desses resultados.

\section{A ANALOGIA NO TEXTO DE SIMMEL}

Nesta seção, tentarei passar uma ideia da variedade de formas que a analogia assume no texto de Simmel, focando nos dois livros que se mostraram mais significativos para a sociologia.

Para o leitor interessado em identificar as analogias de Simmel, é instrutivo considerar as duas versões do conceito que acabei de expor (ou seja, analogia como proporcionalidade e como semelhança funcional). Pode-se também prestar atenção aos recursos expressivos empregados por Simmel para sinalizar suas analogias. Há toda uma gama de meios de expressão que podem, com maior ou menor precisão, imprimir no texto a marca do procedimento analógico; deles, o mais trivial é a palavrinha "como". ${ }^{18}$ 
Observando este tipo de coisa, temos uma ideia do quão numerosas são as analogias presentes no texto de Simmel. Só na Philosophie des Geldes há mais de uma analogia a cada duas páginas; em números brutos, é possível identificar mais de 700 analogias nessas duas obras somadas (ver Bárbara, 2012: 535). Mas, além de numerosas, as analogias simmelianas também são especialmente variadas. A seguir, exponho dois eixos básicos em que podemos registrar tal variação.

O primeiro é o eixo temático. Depreende-se da leitura de Simmel que ele busca articular o tema central das duas obras aqui em pauta (num caso o dinheiro e, no outro, a sociologia e as formas de socialização) a temas pertencentes aos mais diversos contextos cognitivos. Para passar uma ideia do ponto, basta observar que, na Soziologie, Simmel estabelece analogias entre essa forma emergente de conhecimento e todos estes domínios científicos e culturais: mecânica, geometria, biologia, linguística, teatro, psicologia, geografia, aritmética, astronomia, música, filosofia, poesia, pintura, ótica, lógica, direito e economia. Evidentemente, algumas destas analogias recebem um destaque maior que outras; no primeiro capítulo da Soziologie, por exemplo, Simmel põe em jogo analogias geométricas e biológicas, empregando-as para elucidar certas questões ligadas aos fundamentos da sociologia. Já na Philosophie des Geldes, Simmel compara o dinheiro a deus e ao diabo, bem como à obra de arte, à palavra falada, à lei natural, à faísca, ao conceito de temperatura, ao mar, à energia, ao éter luminoso, ao sangue etc.

Essa grande envergadura temática é crucial para o estilo simmeliano, que preza tanto pela capacidade de adaptação ao maior número possível de conteúdos e objetos distintos como pela capacidade de transpor as fronteiras convencionais entre os vários domínios do conhecimento - duas facetas do ideal da plasticidade. Nessa chave, fica claro que a analogia é o mecanismo predileto de Simmel para realizar essas passagens de um domínio a outro.

O segundo eixo de variação das analogias de Simmel diz respeito à sua contribuição para a solução dos problemas cognitivos que ele se propôs a enfrentar. Podemos chamar esse eixo de funcional, por dizer respeito à função da analogia na realização das metas intelectuais de Simmel. Para caracterizar as várias contribuições específicas da analogia, precisamos apreciar as diferenças entre a proposta básica que orienta os esforços de Simmel como sociólogo e aquela que orienta seus esforços filosóficos. O fato de que essas duas propostas estão interligadas, sendo como dois papéis interpretados pelo mesmo ator, não nos impede de distinguir o que Simmel almejava ao atuar como sociólogo do que almejava ao atuar como filósofo, e gostaria de propor que suas analogias adquirem funções distintas em cada um desses contextos cognitivos. ${ }^{\text {I9 }}$

Comecemos pela Soziologie. Grosso modo, podemos aqui distinguir as analogias mais ilustrativas daquelas com maior valor cognitivo para a socio- 
logia. ${ }^{20}$ Quando Simmel, por exemplo, sugere que "as ondas estão para o mar, assim como os indivíduos, para a sociedade" (Simmel, I992: I4), ou quando compara a nobreza a uma ilha (Simmel, I992: 826-827), temos uma analogia de orientação mais puramente ilustrativa. Nesses casos, Simmel vale-se de uma imagem familiar (isto é, já presente no repertório do senso comum) como expediente retórico para chamar a atenção para um aspecto que julga pertinente do problema sob exame (a sociedade, a nobreza). Cerca de um quarto das analogias presentes na Soziologie encaixam-se nessa classe. ${ }^{21}$

As analogias de maior valor cognitivo para a sociologia admitem maiores subdivisões. Podemos, primeiro, separar analogias que operam "dentro" do domínio que Simmel destina à sociologia das que operam "para fora" dele, articulando-o a outros contextos cognitivos. Para classificar essas analogias que transcendem a sociologia (cujo conjunto corresponde a quase um terço das analogias presentes na obra em questão) podemos nos valer da "divisão do trabalho científico" proposta por Simmel, para quem a sociologia, como toda ciência exata, possuiria certos limites inferiores, em que se cairia na epistemologia, e certos limites superiores, que seriam da alçada da metafísica (ver Simmel, 2006: 35-36). As inúmeras analogias entre a sociologia e outros domínios científicos que mencionei encaixam-se no primeiro caso; mas Simmel também se serve de analogias para "extrapolar" a sociologia. Este é o caso de suas analogias entre fenômenos psicológicos e sociológicos, como aquelas entre nossos conflitos "internos" ou individuais, e os conflitos sociais. Simmel reserva todo um excurso à discussão deste tipo de analogia, que, nas suas palavras "não é em si e para si de natureza sociológica, mas sim de natureza social-filosófica, já que seu conteúdo não é um conhecimento da sociedade, mas um nexo geral que encontra na forma social apenas um de seus exemplos" (Simmel, I992: 850).

Implícito a isso é que há certas analogias "de natureza sociológica", ou seja, que operam "dentro" dos limites que Simmel estipula para a sociologia. Há mesmo grande número delas: cerca de duas em cada cinco analogias da Soziologie enquadram-se aí. A maior parte delas segue o modelo da semelhança funcional, ligando duas ou mais formações sociais concretas, como no caso das leis de Tebas e Corinto. Simmel utiliza suas analogias não só para comparar formações sociais "acabadas", como também para comparar processos sócio-históricos de escala variada. ${ }^{22}$ Por fim, ele também recorre à analogia para mapear certas correlações entre formas depuradas de socialização, que diferem das formações sociais concretas por seu maior grau de estilização e de abstração histórica (sendo, por isso mesmo, mais fáceis de encaixar no modelo proporcional de analogia do que as correlações entre formações históricas concretas, que via de regra seguem o modelo da semelhança funcional). Este é o caso de suas analogias entre o adorno e o segredo (Simmel, I992: 4I4), ou entre a luta esportiva e as disputas jurídicas (Simmel, 
I992: 305). No grosso dos casos em que Simmel constrói analogias "de natureza sociológica", seu objetivo é capturar certo padrão ou regularidade comum aos casos comparados - buscando, assim, ordenar o material da experiência.

Passemos agora à Philosophie des Geldes. Temos aqui uma importante mudança de ênfase. Para começar, observo que sua filosofia pretende incorporar os resultados do desenvolvimento científico, ou, para ficarmos com uma imagem mais simmeliana: passar por eles em seu percurso filosófico. Por isto, há aqui também um bom número de analogias de "natureza sociológica”, a que é possível somar algumas de natureza psicológica (que, aliás, também aparecem na Soziologie), histórica, econômica e mesmo biológica ${ }^{23}$ que são da mesma família das analogias sociológicas, com a diferença de que, aqui, servem ao propósito de ampliar o alcance de sua aventura filosófica.

Em linha com a classificação proposta para a sociologia, podemos imaginar que essas analogias, embora levem à filosofia simmeliana, não são ainda de "natureza filosófica"; teríamos, além delas e das propriamente filosóficas, algumas com valor apenas ilustrativo. Mas, no contexto da Philosophie des Geldes, temos de lidar com a complicação de que Simmel é explícito em sua pretensão de operar num registro em que as dimensões estética e cognitiva devem funcionar em conjunto. ${ }^{24}$

Como resultado disto, os limites entre analogias ilustrativas e filosóficas acabam se borrando no contexto da filosofia simmeliana. O que podemos fazer aqui é distinguir entre analogias que ilustram diretamente o objeto específico dessa filosofia (no caso, o dinheiro e a economia monetária) daquelas que ilustram objetos distintos, de importância mais indireta nesse contexto. ${ }^{25}$ Nesta última categoria encaixa-se, por exemplo, a analogia segundo a qual a finalidade de uma ação propositiva parece amiúde estar para o agente, assim como o horizonte para alguém que caminha em terra firme (Simmel, I989b: 303). A ideia aqui é elucidar um aspecto da relação entre o agente e suas ações propositivas (a saber: a circunstância de que muitas vezes parecemos perseguir um fim inatingível), cuja relação com o dinheiro é explorada em outro ponto do percurso filosófico de Simmel.

Da mesma forma, várias das analogias que têm como um de seus termos o dinheiro ou a economia monetária visam ilustrar cada qual um aspecto particular do objeto de sua filosofia, como nos casos das analogias entre deus e o dinheiro (Simmel, I989b: 305) e entre este e o diabo (Simmel, I989b: 276-277). Contudo, algumas delas destacam-se por exprimir algo que Simmel considera ser uma conexão intrínseca ou essencial entre este objeto particular e a existência em geral. A diferença é que, nestes casos, a pretensão de Simmel é desvelar uma regularidade mais elementar, identificando a "razão" que outorgaria verdade e expressividade às analogias mais particulares com o dinheiro. É o caso da seguinte passagem sobre a "proporcionalidade fundamental" da economia, que Simmel considera ser uma condição de possibili- 
dade do mundo econômico: "Pressupondo o equilíbrio perfeito de todas as oscilações e irregularidades acidentais na formação do preço, então, num dado circuito de dinheiro, mercadoria e troca, cada mercadoria estaria para seu preço, assim como o total das mercadorias economicamente ativas num dado momento para o total de dinheiro ativo nesse mesmo momento" (Simmel, I989b: I44). Para os nossos fins, o que interessa é que esse tipo de analogia é concebida como uma conexão universal entre as coisas, que transcende a realidade imediata e lhe confere congruência, sendo, por conseguinte, o "alvo" de suas considerações filosóficas. Não há dúvidas da forte carga metafísica ou especulativa destas ideias, que as torna questionáveis, se tomadas ao pé da letra. Seja como for, o próprio Simmel apresenta suas razões para insistir no potencial exploratório da especulação filosófica, como ainda veremos.

Isto basta para passar uma ideia da variedade de função que as analogias têm no texto de Simmel. Porém, assim compreendidas, as analogias são apenas registros literários do procedimento analógico. Tais registros interessam menos por si mesmos, e mais por dizerem algo sobre o processo que os gerou - mais ou menos como os fósseis dizem ao paleontólogo algo sobre a vida que povoou a Terra num passado remoto. Pois ainda há algo entre o quadro de referências para o conceito de que Simmel dispunha e as analogias que foram parar no seu texto, e é a isso que voltaremos agora nossa atenção.

\section{A ANALOGIA NAS MÃOS DE SIMMEL}

Em sua monografia sobre Simmel, concluída em I9I9, Kracauer forneceu alguns dos elementos básicos para compreendermos a relação do procedimento analógico com o tipo de pensamento buscado por Simmel. Por isto, tomarei esse texto como ponto de partida da presente discussão.

Como eu havia adiantado, Kracauer introduz este texto tratando da dificuldade envolvida na tarefa de classificar o pensamento de Simmel - dificuldade esta que Kracauer propõe superar sublinhando alguns problemas básicos alheios a Simmel, para em seguida reconstruir o mundo de coisas em que viveria seu pensamento (ver Kracauer, 2004: I43-I44). A seguinte passagem resume bem este último ponto: "O que está sempre no centro de seu campo visual é a pessoa como portadora de cultura e como entidade espiritual amadurecida, que atua e avalia em plena posse de suas energias anímicas, juntando-se a seus semelhantes no agir e sentir comuns" (Kracauer, 2004: I44).

Kracauer detalha esse panorama subdividindo-o em três círculos temáticos, que correspondem (I) às situações e formações sociais; (2) ao ser humano como indivíduo; e (3) ao mundo dos valores e das realizações humanas objetivas. ${ }^{26} \mathrm{Em}$ seguida, propõe reconstruir a maneira como Simmel abor- 
da este material, buscando caracterizar os principais modos de relação entre coisas a que Simmel voltava sua atenção ao embrenhar-se nesses domínios temáticos - sendo a analogia um destes modos de relação.

Kracauer desde o começo enfatiza o papel da analogia no trato com problemas ligados à cultura humana no sentido amplo. Antes mesmo de definir o conceito, busca situá-lo como resposta ao que podemos chamar de empedernimento conceitual; a ideia aqui é que o aspecto prático dos conceitos acabaria sobrepondo-se aos demais, levando a uma espécie de esquecimento das relações entre coisas que não digam respeito a esse aspecto dos conceitos. Reduzido ao que têm de útil, os conceitos tornar-se-iam não só inflexíveis, como ainda incomparáveis entre si (Kracauer, 2004: I52). Este tópico, que teria vários desdobramentos no pensamento alemão, não é nem um pouco estranho a Simmel, como vemos na seguinte analogia:

[...] no domínio puramente intelectual, mesmo as pessoas mais conhecedoras e reflexivas operam com um número sempre crescente de representações, conceitos e sentenças, cujo sentido e conteúdo exatos só entendem de forma inteiramente imperfeita. A tremenda ampliação do material do saber que temos objetivamente à disposição permite, até mesmo obriga o uso de expressões que verdadeiramente passam de mão em mão como recipientes fechados, sem que o conteúdo da reflexão efetivamente ali condensado seja desdobrado diante do usuário particular (Simmel, I989b: 62I).27

O ponto de Kracauer (condizente com o universo conceitual simmeliano, como mostra a passagem acima) é que, com suas analogias, Simmel conseguiria desdobrar o conteúdo reflexivo dos conceitos, até então comprimido pela força dos constrangimentos práticos. Assim, Simmel "livraria as coisas de seu isolamento" (Kracauer, 2004: I53).

Para Kracauer, isto dependeria de que tais analogias não fossem meros frutos da imaginação simmeliana, ou seja, relações meramente "inventadas". Ao contrário: dizer que Simmel estabelece ou constrói analogias equivaleria a dizer que ele descobre certas relações "encobertas" pela força do hábito. Assim, "[...] por mais espirituosa e surpreendente que possa ser uma analogia, é crucial para ela que seja objetivamente verificada; ela é algo que conhecemos, é uma relação dos próprios fenômenos" (Kracauer, 2004: I54-I55).

Esta passagem integra um longo parágrafo em que Kracauer distingue a analogia da metáfora - esta que, ao contrário daquela, é concebida como uma criação da fantasia subjetiva, sendo regida por critérios de ordem estética, e não mais cognitiva (Kracauer, 2004: I53-I55). Em nossos termos, podemos dizer que, pela proposta de Kracauer, o valor expressivo das analogias de Simmel teria, na melhor das hipóteses, menos peso que seu valor heurístico - ou que as analogias de Simmel estariam mais para as de Kant do que para as de Goethe.

Há um problema nessa leitura: neste ponto, Kracauer acaba perdendo de vista a relação entre o aspecto estético e o cognitivo da analogia, para o 
qual Simmel insistentemente aponta (sobretudo em suas obras de orientação mais filosófica). Sintomático disso é que o que Simmel chama de metáfora não se opõe ao que chama de analogia. Para ele, a relação entre uma coisa e outra é mais próxima da concepção que parte de Aristóteles, segundo a qual as analogias dariam o substrato para a formulação e compreensão das metáforas; assim, se compreendemos expressões como "egoísmo de grupo", é porque estabelecemos uma analogia segundo a qual certo fenômeno " $X$ " estaria para o grupo, assim como o egoísmo, para o indivíduo. ${ }^{28} \mathrm{Nesta}$ chave, uma metáfora como a do egoísmo de grupo não é mais uma simples fantasia subjetiva concebida como "exposição das relações entre sujeito e objeto" (Kracauer, 2004: I55), ou seja, não é mais apenas uma tomada de posição frente ao mundo. Pois ela não só depende da referência a um conhecimento intersubjetivamente consolidado (no caso, acerca do que seria o "egoísmo individual"), que transcende e põe em perspectiva a relação entre sujeito e objeto, como também fornece parâmetros para a formulação de algo até então não formulado - formulação essa que já não está apenas sujeita a critérios de avaliação estética. Assim, podemos manipular o tipo de imagem que Kracauer associaria à metáfora para mostrar como, e de que modo, ela diz algo acerca das analogias de Simmel: se estas afinal também são "frutos da imaginação", trata-se aí de frutos cultivados com a finalidade específica de nutrir certas pretensões de conhecimento.

Mesmo concedendo que a leitura de Kracauer acaba desconsiderando a conexão entre o aspecto estético e o cognitivo da analogia, cumpre admitir que ela é informada por uma intuição correta. Pois a questão é que esses dois aspectos não se encaixam sem mais. Há uma tensão sistemática entre eles, que Simmel precisa o tempo todo administrar. No caso de seu projeto de uma sociologia científica, ele tentou resolvê-la "à força", buscando conter tanto quanto possível a dimensão estética em favor da cognitiva. ${ }^{29}$ Pensemos nas analogias propriamente sociológicas: nelas, o objetivo é sempre apanhar algum padrão ou regularidade comum aos casos comparados. Podemos enquadrar perfeitamente tais analogias no conceito proposto por Kracauer, já que, com elas, Simmel busca apontar para relações que podem ser descobertas e verificadas. A definição de Kracauer, pautada pela oposição à metáfora como atitude ou tomada de posição da fantasia, cai muito bem nesses casos justamente porque, ao construir tais analogias, Simmel buscou despojá-las de todo caráter subjetivo, por considerar isso necessário para que sua sociologia pudesse reivindicar o estatuto de ciência.

Mas, como vimos, há uma diferença crucial entre seu projeto sociológico e seu projeto filosófico, que diz respeito ao modo como Simmel propõe encaixar aquelas duas dimensões presentes no seu conceito de analogia. É neste ponto que a distinção proposta por Kracauer se mostra insuficiente. A ideia de que sua filosofia do dinheiro é marcada por um "colorido" estético 
está colocada com todas as letras no Prefácio a tal obra. Nesse contexto, embora a pretensão de conhecimento ainda ponha rédeas no galope da imaginação (concebida como meio para realizar a ambição filosófica de ampliar o repertório do conhecimento humano), é esta que na prática leva Simmel de um lado a outro, sendo como o corcel sem o qual as rédeas não passariam de um punhado de tiras de couro e argolas metálicas sem função.

É claro que essa dimensão estética também está presente no projeto sociológico de Simmel; mas aí ela se impõe a despeito de sua tentativa de suprimi-la, enquanto que no seu projeto filosófico ela é articulada de modo explícito. Por sua vez, a especificidade dessa articulação nos fornece uma chave para dar conta daquelas analogias de orientação filosófica que "apontam" para certa regularidade ao mesmo tempo que lhe conferem um colorido particular - colorido este que já não está vinculado a pretensões de verdade tão fortes como aquelas que seriam de se esperar de uma ciência "exata" (ver Simmel, I989b: 9-I4; Waizbort, 2000: 83 ss.).

Este colorido com que Simmel pretende pintar a realidade ao atuar como filósofo é o colorido da interpretação. Tanto na Philosophie des Geldes como no seu Probleme der Geschichtsphilosophie, ${ }^{30}$ Simmel propõe que a tarefa do intérprete, seja filósofo ou historiador, guardaria certa analogia com a do artista, na medida em que ambos reconstruiriam uma "imagem" da realidade que traria a marca de uma tomada de posição frente a ela - uma imagem que não espelha a realidade, mas, sim, projeta-se sobre ela, que é algo construído e não pode, neste sentido, ser simplesmente descoberto. Nesta chave, assim como dois artistas podem produzir pinturas completamente diferentes a partir de um mesmo tema, sem que nenhuma delas esteja necessariamente "errada", assim também um historiador poderia construir duas interpretações históricas diferentes, mas igualmente válidas, de um mesmo evento. Daí não decorre, claro, que baste propor uma interpretação histórica para validá-la. Embora essa "margem de interpretação" pressuponha um gesto do arbítrio e uma tomada de atitude, não se resume a tal pressuposto. A pretensão de Simmel ao discutir os problemas da filosofia da história é precisamente articular a dimensão objetiva e a subjetiva do conhecimento histórico, mostrando como seria possível que uma "criação da fantasia" tenha como resultado um incremento cognitivo, como uma imposição da imaginação criativa sobre realidade seria capaz de nos dizer algo verdadeiro a seu respeito.

Encontramos aqui outra face da discrepância entre o projeto sociológico e o filosófico de Simmel. Ainda que reconheça que as formas de socialização por ele investigadas têm algo de construído (Simmel, I992: I78-I79), , ${ }^{\text {I }}$ ele não apresenta sua sociologia como uma sociologia interpretativa. Isso não o impediu de fazer uma sociologia que pode ser corretamente interpretada nessa chave. Mas ainda precisamos remeter ao seu projeto filosófico para efetuar tal interpretação, pois seu projeto sociológico não traz esse compo- 
nente interpretativo no plano da explicitação teórica - como fariam Weber e, com maior grau de elaboração, Schütz. Daí que o caminho mais direto para "ilustrar" a aplicação sociológica do procedimento interpretativo em Simmel se encontre não na sua Soziologie, mas, sim, na teoria do moderno contida em obras que ele mesmo considerava filosóficas. Também aqui, certo tipo de analogia ganha destaque, como fica claro na última seção do capítulo final da Philosophie des Geldes - em que Simmel recorre às analogias da distância, do ritmo e da velocidade para destacar certos aspectos do estilo de vida moderno e, assim, construir uma interpretação do presente que até hoje continua frutífera. ${ }^{32}$

Este é, aliás, apenas um exemplo dentre inúmeros outros de como Simmel recorre à analogia para articular alguma ideia ou linha argumentativa importante para sua empresa intelectual. Essa estratégia é tão frequente que não há como evitar a conclusão de que a analogia, a princípio concebida como meio para a realização de fins cognitivos - como, no caso da sociologia simmeliana, a fundamentação de uma nova forma do conhecimento, que se pretende capaz de articular de maneira inédita toda uma gama de conteúdos cognitivos ligados ao domínio mais geral da cultura humana, ${ }^{33}$ e, no caso da filosofia, a aplicação da reflexão a conteúdos até então em geral ignorados pelos filósofos ${ }^{34}$ - tenha se convertido numa espécie de fim em si mesmo.

Para termos uma ideia de quão indispensável a analogia tornou-se para Simmel, podemos imaginar como ficariam sua Soziologie e sua Philosophie des Geldes, caso apagássemos as mais de 700 analogias que podem ser ali encontradas. Não teríamos, então, obras simplesmente mais curtas, mas, sim, obras sem sentido. Afinal, como Simmel, no primeiro capítulo da Soziologie, fez para demarcar o campo de atuação e a especificidade da ciência que pretendera fundar? Trabalhando sobre a analogia de método entre a sociologia e a geometria. Como é que encarou os problemas de definição implicados nessa mesma tentativa? Explorando uma analogia biológica. Como em geral coordenava os inúmeros exemplos apresentados ao longo da Soziologie? Juntando-os por analogia. Como fazia para extrapolar as conclusões obtidas em suas investigações sobre as formas de socialização, para aplicá-las a questões de escopo metafísico? Apoiando-se em analogias. Como descreveu a filosofia em geral e a particularidade da sua filosofia no prefácio à Philosophie des Geldes? Combinando uma analogia espacial com outra estética. Como descrevia o objeto dessa filosofia? Em inúmeros casos, por meio de analogias, quando não enquanto uma variedade de analogia (a proporcionalidade). Como, nesse mesmo contexto, resumia e reutilizava os produtos da filosofia à sua disposição? Elaborando analogias. Como relacionava fenômenos aparentemente 
tão diversos como o segredo e o adorno ou deus e o dinheiro? Fazendo analogias. Como amiúde se referia à peculiaridade das coisas? Afirmando que, para tal, não havia nenhuma analogia. Como buscou articular sua interpretação do estilo de vida moderno na sua Philosophie des Geldes? Acionando três analogias capazes de exprimir, nessa ordem, o seu conceito metafísico de espaço (cuja analogia é a distância), o de tempo (cuja analogia é o ritmo) e o da ligação entre ambos (cuja analogia é a velocidade). Como acabou "concluindo" a Soziologie e a Philosophie des Geldes, obras por natureza inconclusivas ou fragmentárias? Fechando-os com uma analogia.35

Assim, cumpre observar que a analogia, graças à qual Simmel pôde se realizar intelectualmente, de fazer uma filosofia do dinheiro e uma sociologia como a do segredo, por outro lado igualmente se impôs como limite além do qual sua imaginação não chegava, como obstáculo para o acesso a partes desse mundo que ele não ousaria (ou conseguia) tomar em mãos; em suma: como o fim propriamente dito de suas investigações, o ponto a que elas chegavam, ou no qual o movimento de seu pensar achava termo. Dessa forma, também elas, embora orientadas pelo ideal da plasticidade e apesar de permitirem que ele "livrasse as coisas de seu isolamento", em muitos sentidos também limitaram o desenrolar de suas ideias. Podemos pensar na analogia como uma espécie de saída a que Simmel se habituou para solucionar problemas cognitivos especialmente difíceis e que talvez pudessem ter sido solucionados com outros meios conceituais - que, porém, permaneceram inexplorados por Simmel.

Ele mesmo sabia que suas aventuras pela filosofia, pela arte e pela sociologia envolviam todo tipo de risco, e foi precisamente para evitar o perigo do empedernimento conceitual que Simmel se orientava pelo ideal da plasticidade. Vejamos o que ele escreve a Marianne Weber, a quem dedicaria seu livro sobre Goethe (tema da carta):

Para mim, o livro é uma espécie de conclusão, uma aplicação derradeira das formações conceituais que vim aplicando. Agora vou trocar as velas e buscar terras inexploradas. Pode muito bem acontecer que a viagem termine antes da costa. Mas ao menos não deve ocorrer comigo o que ocorre com muitos dos meus colegas, que se acomodam no próprio barco como se estivessem em casa, a ponto de acreditarem que o próprio barco seria a terra nova (Simmel, 1959: 240; grifo no original).

Aqui, o resultado da atividade intelectual de Simmel, o ponto de chegada do conhecimento - que corresponde à exploração de porções do real até então desconhecidas -, é ainda figurado como o principal objetivo de sua aventura náutica. Mas esta ênfase preliminar no resultado logo dá lugar à ênfase no processo, precisamente diante da constatação de que essas terras podem muito bem não ser encontradas, ou, em termos menos metafóricos, da falibilidade do conhecimento. Ao cabo, o que importa é, ainda, produzir novos conhecimentos, ampliar o estoque de conhecimento disponível sobre 
o mundo - mas é significativo que, caso isso não seja alcançado, Simmel ainda prefira assistir ao próprio naufrágio a ceder ao que vínhamos aqui chamando de empedernimento conceitual. Se, como propõe Blumenberg, as apropriações desse tipo de metáfora básica dizem algo sobre o mundo da vida em que estava inserido aquele que dela se apropriou, ${ }^{36}$ então podemos conceber o ideal de plasticidade - que aqui não é um ponto de chegada (esse ainda é a ampliação do estoque de conhecimentos), mas, sim, uma referência orientadora, como as estrelas para os navegadores - como um ideal talhado para lidar com um perigo que avulta depois de iniciada a aventura do pensamento. Pois é nesse instante que a possibilidade de que a aventura não o leve a lugar nenhum ganha peso e concretude, abrindo espaço para que a ênfase no resultado (sempre presente nos planos de Simmel) ceda à ênfase no processo, corretamente identificada por seus intérpretes como característica-chave de seu estilo de pensamento, tal como reconheceria o próprio Simmel (ver Waizbort, 2000: II-34). E precisamente nessa chave, o ideal sublime e inatingível da plasticidade deixa de ser algo desatrelado à realidade (ou seja, algo que só podemos contemplar à distância), para tornar-se uma atividade propositiva bem pragmática: diante de um pensamento que ainda não alcançou seu propósito, nada mais apropriado do que a exigência de "seguir em movimento". A contrapartida disso é clara: por força das circunstâncias, o que antes era possibilidade agora aparece como necessidade, de modo que a analogia se torna indispensável para Simmel.

Esse tipo de ajuste de expectativas pode ser detectado com muita clareza na sociologia de Simmel. Estava nos seus planos fazer da sociologia uma ciência exata, mas eventualmente Simmel reconhece que "pode ser que se trate aqui apenas de um princípio e da indicação de um rumo para um caminho interminavelmente longo, e, nesse caso, toda completude sistematicamente fechada seria, quando muito, uma autoilusão" (Simmel, I992: 3I; grifo conforme o original) - uma ilusão análoga àquela de seus colegas, ao confundir o novo mundo com o navio que devia conduzir a ele.

Mas o mesmo ajuste também está presente na sua concepção filosófica, em que aparece assentado na sua teoria do conhecimento. Pois o ponto de partida de Simmel é a ideia de que o conhecimento é falível e mesmo assim possível, de que a possibilidade do conhecimento depende de sua seletividade, que é, por sua vez, um tipo de limitação.

É, portanto, o próprio Simmel quem nos obriga a encarar as limitações desse que era um dos seus recursos prediletos para produzir conhecimento, a analogia. Vejamos o que ele tem a dizer sobre um livro do psicólogo William Stern, cujo prefácio é assinado por Moritz Lazarus, influente professor de Simmel: 
Este livro interessante e engenhoso propõe a tarefa de investigar o papel desempenhado pela analogia no pensamento, no sentimento e na vontade cotidianas. Aponta inúmeros casos em que a criança e o homem ingênuo, em vez de representar diretamente a coisa, serve-se desse rodeio peculiar, aliás precisa dele se servir para obter uma imagem de mundo coerente; e então, de um ponto aparentemente situado à sua margem, recai uma luz cristalina sobre a totalidade do ser espiritual do homem (Simmel, 2005: 298).

É inevitável colocarmos essa passagem da obra de Simmel ao lado desta, mais famosa:

Caso a história das ciências efetivamente mostre que o modo filosófico de conhecimento é primitivo, sendo meramente uma especulação sobre os fenômenos com base em conceitos gerais - mesmo nesse caso, tal procedimento provisório será ainda incontornável frente a várias questões, especialmente as que dizem respeito às valorações e aos nexos mais gerais da vida espiritual, que, até agora, não podemos nem nos furtar a responder, nem responder de forma exata (Simmel, I989b: 9).

Que fique claro: não se trata aqui de "acusar" Simmel de infantilidade ou ingenuidade, tampouco de ceder à fantasia romântica segundo a qual o pensador (seja poeta, filósofo ou sociólogo) deve ser como uma criança eternamente deslumbrada com o mundo ao redor. Trata-se, antes, de enfatizar que Simmel sabia que sua técnica predileta para a articulação de suas ideias era intrinsecamente limitada, não passando de um expediente precário, mas não por isso dispensável, para suprir certas insuficiências de seu pensamento. Trata-se mesmo de ir além da dicotomia entre a intransigência de uma acusação vã de imaturidade e a condescendência idealizadora. Se, no primeiro caso, falharíamos em compreender Simmel por ignorar a situação em que ele se achava, no segundo abdicaríamos de criticá-lo, sob a pressão de acomodar nossa interpretação às limitações do seu pensamento - perdendo com isso a referência sem a qual não podemos mais identificá-las, muito menos confrontá-las. Num caso como no outro, cairíamos nos erros que Simmel pretendeu evitar, nem sempre com sucesso: pintando ou uma figura empedernida demais de suas ideias, ou uma excessivamente floreada.

Essa é, claro, outra face daquele dilema enfrentado pelos intérpretes de Simmel - um dilema que, embora não esteja colocado apenas para os seus intérpretes, é especialmente agudo no seu caso por nascer de uma tensão interna ao seu pensamento. Eis como podemos resumir essa tensão: em suas aventuras pela filosofia, pela sociologia e pela estética, Simmel eventualmente encontrou porções do real que escapavam às suas pretensões de conhecimento, ou seja, com coisas desconhecidas que ele não conseguia converter em objetos do conhecimento. Para exemplificar o ponto, podemos nos ater ao caso de sua sociologia: Simmel nunca soube apreciar o valor cognitivo das generalizações de base estatística para a sociologia, mesmo escrevendo numa época em que já dispunha dos trabalhos de um Durkheim;37 na 
mesma linha, sua dependência bem mais radical do ideal da plasticidade, e, portanto, dos recursos cognitivos talhados para alcancá-lo, está diretamente relacionada à sua desvalorização de estratégias mais sistemáticas de formação conceitual, num franco contraste com um Weber, que, se, por um lado, também favorecia a construção de conceitos maleáveis o bastante para dar conta das flutuações do real, por outro nunca se furtou a examiná-los de forma sistemática, com inegáveis ganhos para a sociologia. ${ }^{38}$ Tudo isso, claro, só foi se configurando como problema à medida que Simmel ia avançando no seu projeto inicial para a sociologia. Digamos que, a essa altura, ele estava em pleno mar, assim como os seus "colegas" na academia alemã; e que sabia que os instrumentos que tinha mais à mão para chegar aonde pretendia (afinal os mesmos disponíveis para os seus colegas) talvez não bastassem. Diante disso, ele apostou no instrumental que lhe pareceu o mais versátil dentre os disponíveis no seu tempo, o que parecia melhor se ajustar a todo tipo de circunstância, o que parecia lhe dar a maior margem de manobra. Como tentei mostrar, a analogia foi, nas suas mãos, o principal desses instrumentos - uma aposta em muitos sentidos adequada, considerando a variedade de usos que esse instrumento em particular recebeu ao longo da história do pensamento ocidental. Hoje, estamos em condições de ponderar que, se esse instrumento mostrou-se útil em diversas ocasiões, como queria Simmel, também o inibiu, apesar de todas as suas intenções em contrário, de explorar tantos outros recursos, como os desenvolvidos naquela época por Durkheim e Weber.

Recebido em 22/II/2014 | Aprovado em Io/o2/20I5

Lenin Bicudo Bárbara é doutorando em Sociologia pela Faculdade de Filosofia, Letras e Ciências Humanas da Universidade de São Paulo (FFLCH-USP). Suas principais áreas de interesse acadêmico são: teoria social, pensamento alemão, teoria do conhecimento em geral, filosofia e história das ciências, e os estudos de gênero. Recentemente, traduziu a Cultura filosófica

(no prelo), de Georg Simmel, e a coletânea Histórias de fantasma para gente grande: escritos, esboços e conferências (2015), com ensaios do historiador da arte alemão Aby Warburg. 


\section{NOTAS}

I Este artigo é uma derivação de minha pesquisa de mestrado, financiada pela Fundação de Amparo à Pesquisa do Estado de São Paulo (FAPESP). Incorporo aqui trechos da dissertação que produzi ao fim do mestrado, ainda que revistos e rearticulados. As traduções de todas as obras que não estão em português foram feitas por mim. Agradeço aos pareceristas anônimos a interlocução sobre o artigo.

2 Décadas depois, a primeira parte desta monografia seria incluída na coletânea de ensaios O ornamento da massa, traduzida para o inglês e, recentemente, para o português.

3 "Filosofia do dinheiro" e "Sociologia", respectivamente.

4 Para um levantamento com pelo menos uma referência de cada autor ao tema, ver Bárbara (2012: 7).

5 Sistema de Lógica, livro III, cap. XX, §I. Sempre que fizer uma referência a obras clássicas ou com várias edições (como a de Mill), acrescentarei no rodapé as informações necessárias para localizar a passagem independentemente da edição utilizada.

6 O que está em conformidade ao tipo de conhecimento que Simmel busca, que se pretende maleável e visa apanhar a realidade em suas nuances, em vez de aferrá-la a definições pétreas.

7 Para uma reconstrução da história do termo no seu contexto de origem, ver Szabó (I978). Observo que Szabó não se concentra na recepção platônica do conceito.

8 A República, 508b-508c.

9 Assim, se ro está para 5 assim como 6 está para " $x$ ", então o único valor possível para "x" é 3 ; e, nesse caso, então Io também está para 6 , assim como 5 para 3 .

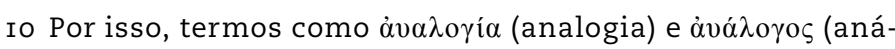
logo) muitas vezes são traduzidos como "proporção" ou "proporcional" nas versões em português das obras aristotélicas.

I I Ética nicomaqueia, II3Ia29-II3Ibi2.

I 2 Poética, I457bi5-I457b35.

I3 A semelhança em questão é nítida quando comparamos a estrutura óssea de ambos os traços. Para uma definição mais precisa do conceito de homologia, ver Mayr (I998: 62-63). 
I4 A linguagem de Simmel é aqui carregada de metáforas biológicas; ele mesmo fala em "condições de vida" e num “instinto" aristocrático.

I5 Heidegger comenta aqui Kant (2010: 210, Crítica da razão pura, B 222).

I6 "Socialização" aqui traduz "Vergesellschaftung”, conceito- chave da sociologia de Simmel. Há quem prefira verter o termo por "sociação" ou "associação", visando evitar confusões com versões distintas do conceito de socialização, que em geral possuem um sentido mais restrito do que a "Vergesellschaftung" de Simmel. Considero essas opções válidas, de modo que meu objetivo aqui não é desautorizá-las; há, contudo, certa controvérsia a respeito do assunto, e, como me foi apontado, mais de uma vez, a importância em justificar essa opção, exponho aqui minhas razões. A principal delas é que a palavra "socialização" parece-me transmitir bastante bem a ideia básica do conceito de Simmel, isto é, a ênfase no processo formativo da sociedade. É verdade que essa opção pode levar a confusões, mas não me parece que as outras opções sejam vantajosas neste quesito, especialmente no caso de "associação". Quanto a "sociação", o uso do neologismo pode induzir o leitor a imaginar que se trata de um conceito original de Simmel, ou mesmo de um termo por ele inventado, o que não é o caso.

I7 Este último ponto é mais uma interpretação minha sobre os achados de Dodd, embora ele mesmo fale em algo parecido ao destacar a "capacidade de revigorar a discussão" própria de algumas das analogias de Simmel. Diga-se que, em minha pesquisa, não fiz o confronto com o texto de Goethe para investigar em detalhe o que Simmel aprendeu com ele acerca da analogia (como fiz com Aristóteles, Kant e Darwin). Parece-me que tal confronto revelaria aspectos ainda mais centrais do que aqueles apontados por Dodd, sobretudo considerando os pontos de contato entre Goethe e Simmel discutidos em Waizbort (2000: 75 ss.).

I8 Em alemão: “wie”. Kracauer (2004: I55) foi quem primeiro chamou a atenção para isso, embora tenha exagerado ao qualificar esse sinal como indispensável. Wolff também especificou alguns desses recursos expressivos (ver Sim- 
mel, I959: ix). No trabalho em que se baseia este artigo, elaborei uma lista mais completa (Bárbara, 2012: 97-II5).

I9 No caso da Philosophie des Geldes, devemos ponderar que essa obra apanha uma porção mais restrita de sua atuação como filósofo, ao passo que a Soziologie condensa a maior parte de sua produção sociológica. Escolhi a Philosophie des Geldes precisamente por seu impacto e interesse para o sociólogo contemporâneo.

20 O que entendo por "analogia ilustrativa" é algo próximo do que Dodd (2008: 432) tinha em mente ao utilizar a mesma expressão; contudo, Dodd contrasta isso com o que chama de analogias substantivas, algo distinto das analogias com valor cognitivo para a sociologia a que me refiro.

2I Para mais detalhes, ver Bárbara (2012: II7-I59 e 534). A referência vale para todas as menções ao número das analogias de Simmel apresentadas nesta seção.

22 Para alguns exemplos, ver Bárbara (2012: I33-I34). No livro sobre as Questões fundamentais da sociologia, Simmel explicita o ganho cognitivo que espera de analogias entre processos sócio-históricos de larga escala (ver Simmel, 2006: 24-25; comento a passagem em Bárbara, 2012: 264-267).

23 Para exemplos disso, ver Bárbara (2012: I5I-I57). Somadas, temos aí cerca de um quarto das analogias da Philosophie des Geldes.

24 Sobre isso, ver Waizbort (2000: 75 ss.). Convém acrescentar que, em alguma medida, a dimensão estética e a cognitiva também acabam vinculadas na sociologia simmeliana. Porém, ao contrário do que se passa com seu projeto filosófico, Simmel busca, ao fazer sociologia, "suprimir" o fundo estético do seu pensamento, por considerar isto necessário dadas as pretensões científicas de sua sociologia - e é essa busca que fundamenta a distinção entre as dimensões estética e cognitiva com que opero.

250 que segue é uma versão simplificada da tipologia proposta em Bárbara (20I2: I4I-I60).

26 Kracauer (2004: I44-I48) dedica um parágrafo a cada uma dessas dimensões. Sua proposta é um claro aceno à teoria da cultura simmeliana: se (2) e (3) correspondem, respectivamente, aos mundos da cultura subjetiva e objetiva, (I) corresponde ao plano das interações e processos que integram os vários "portadores" de cultura. 
27 Pensemos no conceito de analogia: quantas vezes o repassamos, sem nos darmos conta, por exemplo, de sua origem matemática?

28 Esta metáfora (baseada, como vimos, numa analogia) aparece no texto de Simmel (I992: 4II).

29 Esta tendência foi enfraquecendo com o tempo, mas o ponto é que, em algum grau, ela sempre esteve presente.

30 "Problemas da filosofia da história". A analogia com a arte percorre boa parte do primeiro capítulo do livro, em que me baseei para elaborar o parágrafo a que se liga esta nota. Ver, especialmente, Simmel (1997: 286-290).

3I Escolhi esta passagem por ter sido reproduzida e comentada em Cohn (2003: 63 ss.), em que Cohn discute o caráter construído das formas de socialização em Simmel no contexto de uma comparação com Weber.

32 Diga-se que o próprio Simmel (1989b: 657), ao introduzir o assunto, estabelece o vínculo entre tais analogias e o procedimento interpretativo.

33 Simmel formula a questão nesses termos já em I892, no seu livro sobre a diferenciação social, ao falar na possibilidade de uma ciência da sociedade (ver Simmel, I989a: II6-II7).

34 Algo semelhante pode ser detectado na sociologia simmeliana, que eventualmente amplia seu escopo visando formalizar ou pelo menos assimilar fenômenos como a troca de olhares, o perguntar ao outro pelo caminho, o adornar-se para os outros, a gratidão etc.

35 Desenvolvi todos esses pontos em Bárbara (2012).

36 Para quem "as transformações nas metáforas básicas indicam mudanças na compreensão do mundo e na compreensão de si" (Blumenberg, 200I: I40; I993: 3I). Ao investigar a metáfora básica da viagem náutica, o mesmo Blumenberg (I997: 24) comenta a carta de Simmel que acabamos de ler.

$37 \mathrm{E}$, neste contexto, convém apontar que foi com base num argumento de analogia que Simmel questionaria o valor de tais generalizações para a sociologia. Ver Simmel (I992: 63I-632). 
38 Podemos comparar a discussão de Simmel sobre o problema da ação no começo do terceiro capítulo da Philosophie des Geldes (Simmel, I989b: 254 ss.), toda pautada por analogias e metáforas, com a discussão weberiana sobre o tema. Ou, então, a discussão de ambos acerca do problema da dominação. Weber tinha grandes reservas relativamente ao tratamento que Simmel dispensaria a esse problema no terceiro capítulo da Soziologie (Simmel, I992: I60 ss.; Weber, I99I: I2). Isto porque, para ele, a noção simmeliana de interação ou influência recíproca ("Wechselwirkung") seria demasiado inespecífica, a ponto de induzir o sociólogo a desconsiderar os casos de imposição unilateral da vontade de um sobre o outro (o que, aliás, Simmel ilustra por meio de analogias), algo que Weber não podia admitir. Diga-se que essa questão em particular é bem complicada, e merece ser tematizada num artigo à parte; mas no geral me parece que, neste caso, a crítica de Weber acerta o alvo, e que sua discussão consegue incorporar à sociologia uma dimensão do mundo social que Simmel, quase que por definição, tendia a negligenciar: a violência. Claro está que também as propostas de Weber e Durkheim tinham seus pontos cegos; mas como, neste artigo, estamos tratando da proposta simmeliana, só cabe explicitar as limitações desta, e para isso a comparação com esses autores, que afinal trataram de porções do real de que Simmel não tratou com tanto detalhe, parece instrutiva.

\section{REFERÊNCIAS BIBLIOGRÁFICAS}

Aristóteles. (1984). The complete works of Aristotle: The revised Oxford translation. Editado por Jonathan Barnes. Princeton: Princeton University Press.

Bárbara, Lenin Bicudo. (2012). Simmel e a analogia: Investigações sobre o uso e os aspectos epistemológicos da analogia na Soziologie e na Philosophie des Geldes de Georg Simmel. Dissertação de Mestrado. PPGS/Universidade de São Paulo.

Blumenberg, Hans. (1993). Light as a metaphor for truth. In: Levin, David M. (org.). Modernity and the hegemony of vision. Berkeley/Los Angeles: University of California Press, p. 30-62. 
Blumenberg, Hans. (1997). Schiffbruch mit Zuschauer. Frankfurt: Suhrkamp.

Blumenberg, Hans. (200I). Ästhetische und metaphorolögische Schriften. Frankfurt: Suhrkamp.

Cohn, Gabriel. (2003). Crítica e resignação. Max Weber e a teoria social. São Paulo: Martins Fontes.

Darwin, Charles. (1964). On the origin of species: A facsimile of the first edition. Cambridge, MA: Harvard University Press. Dodd, Nigel. (2008). Goethe in Palermo: Urphänomen and analogical reasoning in Simmel and Benjamin". Journal of Classical Sociology, VIII/4, p. 4II-445.

Heidegger, Martin. (1987). Der Frage nach dem Dinge: zu Kants Lehre von den Transzendentalen Grundsätzen. Tübingen: Max Niemeyer Verlag.

Kant, Immanuel. (2010). Crítica da razão pura. Lisboa: Fundação Calouste Gulbenkian.

Kracauer, Siegfried (2004). Siegfried Kracauer Werke, band 9.2: Frühe Schriften aus dem Nachlass. Frankfurt: Suhrkamp. Mayr, Ernst. (1998). O desenvolvimento do pensamento biológico. Brasília: Ed. UnB.

Mill, John Stuart. (I96I). A system of logic ratiocinative and inductive. Londres: Longmans.

Platão. (1965). A república. São Paulo: Difel (2 vols.).

Snell, Bruno. (I992). A descoberta do espírito. Lisboa: Edições 70.

Simmel, Georg. (2006). Questões fundamentais da sociologia. Rio de Janeiro: Zahar.

Simmel, Georg. (2005). George Simmel Gesamtausgabe, vol. I7: Miszellen, Glossen, Stellungnahmen, Umfrageantworten, Leserbriefe, Diskussionsbeiträge I889-1918, Anonyme und pseudonyme Veröffentlichungen I888-I920. Frankfurt: Suhrkamp. Simmel, Georg. (2003). George Simmel Gesamtausgabe, vol. I5: Goethe, Deutschlands innere Wandlung, Das Problem der historischen Zeit, Rembrandt. Frankfurt: Suhrkamp.

Simmel, Georg. (1997). George Simmel Gesamtausgabe, vol. 9: Kant; Die Probleme der Geschichtsphilosophie (I905/1907). Frankfurt: Suhrkamp. 
Simmel, Georg. (1992). George Simmel Gesamtausgabe, vol. I I: Soziologie. Untersuchungen über die Formen der Vergesellschaftung. Frankfurt: Suhrkamp.

Simmel, Georg. (I989b). George Simmel Gesamtausgabe, vol. 6: Philosophie des Geldes. Frankfurt: Suhrkamp.

Simmel, Georg. (I989a). Georg Simmel Gesamtausgabe, vol. 2: Aufsätze und Abhandlungen I887-I890; Über sociale Differenzierung; Die Probleme der Geschichtsphilosophie (1892). Frankfurt: Suhrkamp.

Simmel, Georg. (1959). Essays on sociology, philosophy \& aesthetics. Organizado por Kurt H. Wolff. Nova York: Harper \& Row.

Szabó, Árpád. (1978). The begginings of Greek mathematics. Dordrecht-Boston: D. Reidel.

Waizbort, Leopoldo. (2000). As aventuras de Georg Simmel. São Paulo: Ed. 34.

Weber, Max. (I99I). Simmel als Soziologe und Theoretiker der Geldwirtschaft. Simmel newsletter, I/I, p. 9-I3. 
A VIA ANALÓGICA NO PENSAMENTO DE GEORG SIMMEL

Resumo

Neste artigo, trato do papel do raciocínio analógico no pensamento de Georg Simmel (I858-I9I8), um dos fundadores da sociologia alemã. Meu objetivo principal aqui é apreender as relações entre o procedimento analógico como recurso cognitivo e o estilo de pensamento a que Simmel adere. Como primeiro passo rumo a isso, recolho os fragmentos da história do conceito de analogia que considero mais relevantes para a recepção da parte de Simmel. Em seguida, proponho um breve mapeamento das ocorrências de analogia que podem ser identificadas naquelas obras de Simmel que mais teriam influenciado a sociologia, a saber: a Philosophie des Geldes (I900) e a Soziologie (1908). Finalmente, ataco a questão quanto ao modo como Simmel manejou suas analogias na sua busca por articular tais projetos intelectuais - visando expor o nexo entre esse recurso e o ideal cognitivo da plasticidade, concebido como princípio orientador dominante do pensamento sociológico e filosófico de Simmel.

\section{THE ANALOGICAL PATH IN THE THOUGHT OF GEORG SIMMEL} In this paper I deal with the role of analogical reasoning in the thought of Georg Simmel (I858-I9I8), one of the founders of German sociology. My main goal here is to grasp the relations between analogy-making as a cognitive resource and the style of thought to which Simmel clings. As a first step towards this, I gather the fragments of the history of the concept of analogy that I consider to be the most relevant to Simmel's reception of it. After that, I put forward a synoptic survey of the instances of analogy that can be identified in those of his works deemed to be the most influential to sociology, viz., his Philosophie des Geldes (I900) and his Soziologie (1908). Finally, I face the question regarding how Simmel handled his analogies as he set out to articulate such intellectual undertakings - aiming to lay bare the connections between this resource and the cognitive ideal of plasticity, conceived as a pervasive guiding principle of Simmel's sociological and philosophical thought.
Palavras-chave

Georg Simmel (1858-I9I8);

Analogia;

Pensamento alemão;

História da sociologia;

Imaginação

\section{Keywords}

Georg Simmel (1858-I9I8);

Analogy;

German thought;

History of sociology;

Imagination. 